\title{
Learning Through Equity Trading Simulation
}

Timothy Moffit, Kalamazoo College, USA

Charles Stull, Kalamazoo College, USA

Hannah McKinney, Kalamazoo College, USA

\begin{abstract}
Over the past several decades, colleges and universities have moved away from the traditional chalk-and-talk lecture. Professors have experimented with a myriad of methods to engage students more fully. Some of the innovations that have been used have succeeded in improving student performance and satisfaction. In this paper we report the learning results of using an equity trading simulation across three different classes at a small Midwestern liberal arts college. Sixty-one students participate in a nine-week equity trading simulation exercise. All class levels are represented, and students with a range of prior courses in business and economics are included. Assessment tools include a pre-simulation survey, a pre-simulation investments test, a post-simulation survey, a post-simulation investments test, and simulation performance. The simulation allows trades in all U.S. equities including ADRs. Trades use actual delayed market prices with a 20-minute delay in order execution. No actual investments are made. The students are given a test before the simulation began to assess their incoming knowledge of investment fundamentals. None of the three classes covers this material in lecture. The students have access to online investments resources and information during the simulation via the simulation service provider. A test is given on the same investment fundamentals after the simulation is completed. The students are also surveyed as to their motivation, interest and satisfaction. Initial results show an average 14-point difference (out of 100) between the pre and post-simulation test scores. This is significantly different from zero at better than the 99 percent level. The gains in performance are higher for the students with the lower pre-simulation test scores. Pre-simulation test scores are significantly higher for students who have taken more business and economics classes. Interestingly, post-test scores show no significant relationship to the number of prior courses in business and economics suggesting that the simulation effectively delivers content to students with limited backgrounds. Survey results show that 64 percent of students regularly use the online education resources provided as part of the simulation, while 97 percent report using outside resources to inform their decisions. Sixty-six percent report the simulation is effective or very effective at increasing their knowledge of investments. Most students, 86 percent, indicate that the simulation increased their interest (a little or greatly) in investments and equity markets.
\end{abstract}

Keywords: Simulation, Equity Trading, Experiential Learning

\section{INTRODUCTION}

$\mathrm{n}$ the second lecture, The School and the Life of the Child, he [Dewey] tells of his search for desks and chairs to use in the Elementary School and of the dealer, 'more intelligent than the rest,' who made this remark: 'I am afraid we have not what you want. You want something at which the children may work; these are for listening' (Blewett, 1960, p. 98).

Dewey (1916), a pioneer in experiential learning, argued for curricula that accommodate activity-based learning. He boldly developed the theory that "learning means something which the individual does when he studies. It is an active, personally conducted affair" (p. 335). Kolb (1984) expands on Dewey's concept of education as a social function in developing his (Kolb's) Experiential Learning Model. Kolb contends that knowledge is created and recreated through deliberate, reflective experimentation. 
The extension of experiential learning to post-secondary instruction in business administration and finance is extensive and evolving rapidly with technology. The case method is widely used and generally regarded as effective pedagogy for business education. Christensen (1989) notes that case teaching methodology has been used since the early 1930's. Similarly, spreadsheet models and applications have dramatically expanded the analytical tool box with which students can assess practical finance problems (e.g., Arnold \& Henry, 2005; Barry, 2004; Dow \& Newsom, 2004; Mukherji, 2003). In a survey of 244 AACSB-accredited MBA programs, Baker and Schomburg (2003) determine that 40 percent of the programs offer field studies to help bridge the gap between theory and practice. A more recent development in experiential education for undergraduate finance students is web-based trading simulation exercises. McClatchey and Kuhlemeyer (2001) find that more than 600 instructors at over 600 institutions use stock market trading and portfolio management simulations in their finance classes.

A number of authors have studied the impact of using trading simulation exercises in finance related courses. Alonzi, Lange, and Simkins (2000) study student feedback regarding a futures trading simulation and find that the experiential nature of the simulation exercise contributes to student learning and enjoyment. Koppenvaer (1993) similarly uses student surveys to evaluate the usefulness of bank simulation software packages. He finds that certain learning outcomes are not evaluated equally across software packages. King and Jennings (2004) study the relationship between trading simulation exercises and student learning to determine whether trading simulation enhances the learning of a traditional chalk-and-talk pedagogy. They find student learning increases when the pedagogy includes trading simulation as an experiential learning component. Lekvin (2005) uses trading simulation software to measure students' trading abilities and to determine if there is any relationship between students' academic performance and trading skills. Ascioglu and Kugle (2005) employ a trading simulation to assess student learning and enjoyment of the learning exercise. They use a student survey to measure the effectiveness of the simulation in meeting learning and enjoyment objectives.

This study is different from prior research in this area. We seek to measure the learning effects of simulation pedagogy via pre-simulation and post-simulation matched pair test results, rather than with simulation performance or student feedback measures. Moreover, we seek to measure the learning effects of simulation without formal instructional support. The question we seek to examine empirically is: Do web-based trading simulation exercises affect learning?

This paper proceeds as follows. The next section describes the web-based simulation program and the game parameters that we employ in this study. This is followed by a presentation and discussion of the results of the simulation exercise. The final part of this paper offers some concluding comments and discussion of areas for further study.

\section{METHODOLOGY}

\section{Investopedia.com $^{\mathrm{SM}}$}

To affect virtual online trading stock market simulation, this study employs Investopedia.com $^{\text {SM }}$ (Investopedia), a web-based stock market simulator that supports equity and options trading on all U.S. major exchanges. The service allows educators and private groups (e.g., investment clubs) to create "private trading games" within the virtual structure to promote formal learning environments and assessment. Investopedia allows the private groups to customize certain trading parameters to meet the group's learning and performance objectives. For this study, Investopedia trading rules are set as follows:

1. 20-minute delayed feed with 20-minute delayed trading

2. Trades executed at market price

3. A per market order fee of $\$ 9.95$

4. A per limit order fee of $\$ 19.95$

5. A beginning cash balance of $\$ 250,000$

6. No security can account for more than $25 \%$ of portfolio value

7. $\quad$ No options trading allowed, and

8. Traded securities are limited to U.S. equity instruments (ADR's included). 
Investopedia manages rules compliance internally through its software. Because equity investments are the most familiar and most common to the lay investor, which by extension to this study is the student with little or no interest or experience in business, this study limits trading to long positions in publicly traded equities.

A primary goal of this study is to encourage participation in the stock market simulation exercise to the extent that learning effects can be measured. Without participation, there can be no learning. Thus, to ensure participation and the potential for learning, two additional trading parameters are added outside of the simulation program by the course faculty. These parameters are:

1. Invested funds must be at least 95 percent of portfolio value at all times, and

2. A minimum of three trades must be executed per week.

Course faculty monitor compliance with these rules weekly. Failure to comply with these rules results in monetary fines assessed to the student's portfolio. For each day that invested funds fall below the $95 \%$ threshold, a $\$ 1,000$ fine is assessed. For each week during which fewer than three trades are executed, a $\$ 2,500$ fine is levied.

The Investopedia web site has extensive investment learning resources that are provided at no charge. The site has numerous investing tutorials, an investing basics newsletter that can be automatically sent to subscribing participants each week; there is a corresponding archive of previous articles and articles of specific investment subjects (e.g., stocks, bonds, active trading, and mutual funds). The site also has an investment dictionary, including buzzwords, and examination preparation questions for the CFA and Series 7 examinations.

\section{Stock Trading Game Methodology}

Game participants. The game participant pool consists of 61 students from a small, residential Midwestern liberal arts college. The participants are students in one of three business classes taught within the department of economics: An introductory business topics class (level 100 course), an introduction to corporate finance class (level 300), and a business senior topics class (level 400). The participants are spread across grade levels, majors and gender.

Knowledge assessment. Investment knowledge is measured before the simulation starts and after it ends. Knowledge is measured on a 100-point scale, using a 50-question multiple-choice test. All questions are weighted equally. To set the context for the assessment, the participants are given the following instructions.

The following quiz has been developed to assist the Department of Economics and Business in assessing the investment knowledge and learning of its students. Although the preliminary exam is intended to establish a knowledge baseline, it is not used in conjunction with subsequent assessment to determine student grades. Because the exam is administered across various populations and subsequently used for comparative analysis, it is critical for respondents to answer the questions to the best of their ability.

Please note that a correct answer is awarded two (2) points, an incorrect answer is penalized one (1) point, and an "I don't know" answer is given zero (0) points. Please read the questions and answers carefully. ${ }^{1}$

The scope of question content includes fundamentals in market mechanics, financial theory, investment theory, and macroeconomic theory. All questions are based on the same or similar questions prepared by government related organizations (i.e., Securities and Exchange Commission, Arizona Corporation Commission, State of Delaware Department of Justice, National Association of Securities Dealers and Securities Investor Protection Corporation). The questions are found on these organizations' web sites.

Curricular role. The simulator runs for nine weeks, concurrent with the ten-week, spring term during which the students take a business related course. Instructions for the game, student surveys and pre-game knowledge

\footnotetext{
1 These instructions appeared at the beginning of both the pre-simulation and post-simulation knowledge assessment examinations.
} 
assessment are clearly articulated and administered during class time at the beginning of the term. The post-game knowledge test and student survey are administered during class time at the end of the term. No other classroom support is provided, and information directly related to the knowledge test is carefully avoided in each course throughout the term. Also, the students do not receive their score on the pre-game test nor correct answers to the questions on the pre-game test.

Grading participation and performance. Significant motivation for participating in the simulation exercise is structured into the course grade. The simulation game accounts for 30 percent of the student's final course grade. The course grade is based on taking the pre-game and post-game assessment tests and surveys, making the required number of trades, keeping the required level of funds invested, and earning the highest return on portfolio investment. The scores on and change in scores between the students' pre-game and post-game assessment tests have no effect on the students' course grade. Moreover, students are not rewarded for conducting independent research or for subscribing to Investopedia's investor support materials; also they are not given grade credit for using the web site's learning tools.

\section{RESULTS}

\section{Descriptive Statistics}

We are most interested in measuring the impact of the simulation exercise on students' knowledge of investments and financial markets. Sixty-one students completed the exercise. Three students did not complete all of the information needed for this analysis and were dropped from the study. The distribution of the final sample, by class and gender, is shown in Table 1 .

Table 1

Class Standing and Gender

\begin{tabular}{|c|c|c|c|}
\hline Class & Number & Gender & Number \\
\hline First year & 8 & Male & 35 \\
\hline Sophomore & 9 & Female & 26 \\
\hline Junior & 15 & & \\
\hline Senior & 29 & & \\
\hline Total & $\mathbf{6 1}$ & & \\
\hline
\end{tabular}

The background and experience of the students vary substantially. Some students have completed all of the core classes for the Economics and Business major, while other students have had few or no prior classes in the department. The distribution of majors includes $51 \%$ of the students as Economics and Business majors, while the other $49 \%$ of the participants are spread across various majors in arts, humanities, sciences, and social sciences. This difference in backgrounds results in striking differences on the pre-game knowledge assessment. Scores range from a minimum of 3 points to a maximum of 69 points. The average score was 32.6 points with a standard deviation of 17.8 .

If the stock market simulation is an effective pedagogical tool, we expect the post-game scores to increase. These scores are substantially higher. The mean post-game score is 46.3 points with a standard deviation of 16.2. The range is from 14 to 78 . We formally test the hypothesis, and find a significant difference in means at more than the $99 \%$ confidence level. This supports the use of the simulation as an effective teaching tool.

Most students improve their scores substantially, although a small number perform worse on the post-game assessment. The average increase is 13.7 points, a $42 \%$ increase in average scores. The largest increases come from students who have lower scores on the initial assessment.

The performance is noticeably different by class (Table Two). First-year students have the lowest pregame score $($ mean $=18.9$ points $)$. Sophomores have higher pre-game scores $($ mean $=28.1)$ and Juniors and Seniors have even higher initial scores (means were 38.9 and 35.4, respectively.) Each group improves on average on the post-test. The younger students have much larger increases. 
Table 2

First-year Students $\mathrm{n}=8$

\begin{tabular}{|c|c|c|c|c|}
\hline Variable & Mean & Std. Dev. & Min & Max \\
\hline pregame & 18.875 & 14.41663 & 6 & 47 \\
\hline postgame & 38.25 & 18.1088 & 14 & 70 \\
\hline change & 19.375 & 10.45996 & 1 & 31 \\
\hline
\end{tabular}

Sophomores $\mathrm{n}=9$

\begin{tabular}{|c|c|c|c|c|}
\hline Variable & Mean & Std. Dev. & Min & Max \\
\hline pregame & 28.11111 & 23.76681 & 3 & 67 \\
\hline postgame & 43.44444 & 17.11075 & 23 & 74 \\
\hline change & 15.33333 & 11.92686 & 3 & 34 \\
\hline
\end{tabular}

Juniors $\mathrm{n}=15$

\begin{tabular}{|c|c|c|c|c|}
\hline Variable & Mean & Std. Dev. & Min & Max \\
\hline pregame & 38.93333 & 14.61636 & 18 & 63 \\
\hline postgame & 51.2 & 15.7035 & 28 & 78 \\
\hline change & 12.26667 & 9.595138 & -10 & 26 \\
\hline
\end{tabular}

Seniors $n=29$

\begin{tabular}{|c|c|c|c|c|}
\hline Variable & Mean & Std. Dev. & Min & Max \\
\hline pregame & 34.51724 & 16.57153 & 9 & 69 \\
\hline postgame & 46.86207 & 15.48669 & 19 & 70 \\
\hline change & 12.34483 & 13.78217 & -9 & 46 \\
\hline
\end{tabular}

Student performance also differs by gender (Table 3). The average score for male students is much higher than the average score for female students. This is true for both the pre-game assessment and the post-game assessment. Females appear to enter these classes with less knowledge of finance and investments. However, the average change in scores is similar (no statistically significant difference), so the simulation seems to be an effective learning tool for both males and females. Based on the post-game scores, both groups improve but females do not catch up to their male counterparts. This suggests further research on gender pedagogy in finance would be valuable.

Table 3

Pre-game and Post-game Scores by Gender

male $n=35$

\begin{tabular}{|c|c|c|c|c|}
\hline Variable & Mean & Std. Dev. & Min & Max \\
\hline pregame & 40.02857143 & 18.27162009 & 6 & 69 \\
\hline postgame & 54.25714 & 13.27391 & 29 & 78 \\
\hline change & 14.22857 & 12.18264 & -10 & 46 \\
\hline
\end{tabular}

female $n=26$

\begin{tabular}{|c|c|c|c|c|}
\hline Variable & Mean & Std. Dev. & Min & Max \\
\hline pregame & 22.61538 & 11.27148 & 3 & 46 \\
\hline postgame & 35.57692 & 13.52087 & 14 & 62 \\
\hline change & 12.96154 & 12.34012 & -4 & 36 \\
\hline
\end{tabular}

We suspect that the large differences in pre-game scores may be due to knowledge gained in other economics and business classes. When we prepare a scatter plot of the pre-game scores as a function of number of economics and business classes, there is visually a clear positive relation. The regression coefficient for number of classes is positive and significantly different from zero. This, of course, does not establish cause.

After participating in the simulation, the scores are higher for most of the sample, but the gains are disproportionately high for students who have fewer pre-game classes in economics and business. Based on this evidence, the less-experienced students (i.e., fewer economics and business classes) seem to have substantially 
caught up to the more-experienced students (i.e., more classes). The relation between score and prior classes is no longer statistically significant.

\section{Regression Analysis}

Pre-game knowledge. We explore the relation between pre-game scores and other variables using regression analysis. These results are shown in Table 4 . Model 1 shows the number of classes is strongly associated with the pre-game assessment score. Students, on average, scored nearly 2 points higher for each economics and business class they have taken. This is a statistically significant relation.

Table 4

Prior Knowledge

Dependent variable is Pre-game score

\begin{tabular}{|c|c|c|c|}
\hline Variable & Model 1 & Model 2 & Model 3 \\
\hline Constant & $22.39 * * *$ & $30.06 * * *$ & $26.76 * * *$ \\
& $(6.98)$ & $(10.62)$ & $(9.68)$ \\
\hline \# of classes & $1.79 * * *$ & $1.97 * * *$ & $1.58 * * *$ \\
& $(4.11)$ & $(5.70)$ & $(4.70)$ \\
\hline Gender dummy (female =1) & & $-19.60 * * *$ & $-14.43 * * *$ \\
& & $(-6.06)$ & $(-4.35)$ \\
\hline Interest dummy & & & $14.07 * * *$ \\
& 0.22 & 0.52 & $(3.47)$ \\
\hline R-squared & & & 0.61 \\
\hline
\end{tabular}

(t-statistics in parentheses)

$* * *$ significant at $99 \%$ level

** significant at $95 \%$ level

* significant at $90 \%$ level

Model 2 looks at gender effects using a dummy variable $(1=$ female). This regression shows female students scoring nearly 20 points below male students, after controlling for the impact of number of classes. This result is also statistically significant above the $99 \%$ level.

The third model adds students' self-declared interest in financial markets or investments. A dummy variable was included for students who expressed "very high" interest in financial markets. These students, on average, scored 14 points higher on the pre-game simulation, controlling for the number of classes and gender. This is also statistically significant.

The relations shown in these models are generally intuitive. We would expect students with more background in economics and business to have more market knowledge, and it's not surprising that students with a very high interest in financial markets will also have substantially more market knowledge than their classmates. The gender difference is surprising. We didn't have any a priori expectation here, and the magnitude of the difference is large. Based on this sample, it appears that female students enter these courses with substantially less investments knowledge than their male peers. This may have important pedagogical implications.

Learning. Students report that the simulation exercise is effective at increasing their knowledge of investments. (The students do not have access to the assessment scores when answering this question.) Only two students indicate the simulation exercise is not effective for them. To the question "How effective was the simulation at increasing your knowledge of investments?", sixty-four percent of the students indicate the simulation is effective or very effective at increasing their knowledge. This is supported by our finding that there is a statistically significant increase in post-game scores relative to pre-game.

We compare this self-reported increase in knowledge to the change in the students' test scores. We expect students who reported that the simulation was very effective would show bigger improvements in knowledge. Surprisingly, the data do not support this idea. Each group's average score improved, but the students who said the 
simulation is not effective had only a slightly lower increase than students who said the simulation is somewhat effective, effective, or very effective. The average increases for the four groups are 11.5 (not effective), 12.1 (somewhat effective), 14.0 (effective), and 14.7 (very effective); the differences between these figures is not statistically significant.

One explanation for this result, or absence of result, is that students may have a broader definition of learning than what we capture using the difference between pre-test and post-test scores.

We use regression analysis to explore the relation between learning, as measured by our assessments, and other variables (Table 5). Model 1 shows that students who have lower pre-game scores have a larger increase in post-scores. This is shown by the statistically significant negative coefficient on the pre-score variable.

Model 2 adds a dummy variable for self-reported learning. The variable takes a value of one for students who said the simulation is effective or very effective at increasing their own knowledge of investments. We expect a positive relation. The coefficient has a negative sign, but it is not significantly different from zero. This may be due to the multiple kinds of learning possible in the simulation.

Model 3 looks at self-reported motivation. Fifty percent of the students said "learning about the markets/stocks" is an "extensive" motivational influence on their participation in the simulation game. We use a dummy variable to capture this motivational effect. We expect a positive relation between motivation and actual learning, but find a negative, insignificant result.

Table 5

Regression Analysis: Learning Dependent variable is "Learning" (Post-game score minus Pre-game score)

\begin{tabular}{|c|c|c|c|}
\hline Variable & Model 1 & Model 2 & Model 3 \\
\hline Constant & $23.78 * * *$ & $24.54 * * *$ & $25.70 * * *$ \\
& $(8.06)$ & $(6.09)$ & $-0.32 * * *$ \\
& $-0.31 * * *$ & $-4.08)$ \\
\hline Pre-game & $(-3.97)$ & $(-3.87)$ & \\
\hline Self-reported learning & & -0.86 & \\
dummy & & -0.28 & -3.11 \\
\hline Learning motivation dummy & & & $(-1.10)$ \\
\hline R-squared & 0.21 & & 0.23 \\
\hline
\end{tabular}

(t-statistics in parentheses)

*** significant at $99 \%$ level

** significant at $95 \%$ level

* significant at $90 \%$ level

\section{CONCLUSION}

The stock market simulation is an effective pedagogical tool. Students display significant gains in their knowledge of financial markets without lectures or assigned readings on these topics. Students find the exercise engaging and use various resources on their own. The grading structure we use motivates participation in the simulation, but there is no reward for doing well on the assessments. The simulation seems to have given substantial self-motivation to learn about these markets. Learning is particularly evident among students with less background in economics and business, suggesting this particular simulation is most effective for those students.

Our findings on gender point to a striking need for more research in this area. Female students score significantly lower on both the pre-game and post-game assessments. The simulation did increase knowledge for both females and males, but even after the exercise the difference in scores is large. Given the growing importance of financial literacy in today's society, this is a major educational issue. Replicating this study at other colleges and 
universities is an important next step. If the gender disparity is widespread, it would indicate the urgent need for further research on curricula and pedagogy that are effective for female students.

Another finding that suggests an avenue for future research is the disparity between students' self-reported learning and their change in test scores. One explanation could be simply that students are not good judges of their own learning. A more interesting alternative is that there are many dimensions of learning and students are cognizant of their own learning across these different areas. Our assessment instrument focused on a particular subset of financial knowledge. Students may well have learned things beyond the test. Exploration of this area may prove to be valuable. Perhaps a multi-dimensional assessment tool could be developed for testing and assessing investments and financial markets knowledge.

From our experience, further use of trading simulations in teaching and further research in this area would be worthwhile. For example, a randomized, controlled experiment with a large number of subjects could be used (Pozo \& Stull, 2006), and this is just one of the many ways that this line of inquiry could contribute to a more enjoyable and effective finance pedagogy.

\section{AUTHOR INFORMATION}

Timothy Moffit is Assistant Professor of Economics and Business at Kalamazoo College and owner of Stratford Valuation Advisors, LLC. Tim Moffit's teaching fields include Corporate Finance, Investments and Financial Statements Analysis.

Charles Stull is Senior Instructor of Economics and Business at Kalamazoo College. Chuck Stull's teaching fields include industrial organization, law and economics and statistic methods.

Hannah McKinney is Professor of Economics and Business at Kalamazoo College and has served as mayor or vice mayor of Kalamazoo, Michigan for the past 12 years. Hannah McKinney's teaching fields include urban economics and public policy and finance.

\section{REFERENCES}

1. Alonzi, P., Lang, D. \& Simkins, B. (2005). An innovative approach in teaching futures: A participatory futures trading simulation. Financial Practice and Education, 20(1), 228-238.

2. Arnold, T. \& Henry, S.C. (2005, Spring). An Excel application for valuing European options with Monte Carlo simulation analysis. Journal of Financial Education, 31, 86-97.

3. Ascioglu, A., \& Kugle, L.P. (2005, Summer). Using trading simulations to teach microstructure concepts. Journal of Financial Education, 31, 69-81.

4. Baker, H. K., \& Schomburg, A., Jr. (2003, Summer). Integrating theory and practice: The role of MBA field studies. Journal of Financial Education, 29, 34-49.

5. Barry, M. J. (2004, Winter). Using Excel to solve the unequal lives, unequal costs of capital problem. Journal of Financial Education, 30, 32-45.

6. Blewett, J. (1960). John Dewey: His Thought and Influence. New York: Fordham University Press.

7. Dewey, J. (1916). Democracy and Education. New York: The Free Press.

8. Dow, B.L. III, \& Newsom, P.D. (2004, Fall). Integrating simulation and sensitivity analysis in a dynamic capital budgeting spreadsheet. Advances in Financial Education, 2, 58-69.

9. King, D. A., \& Jennings, W.W. (2004, Summer). The impact of augmenting traditional instruction with technology-based experiential exercise. Journal of Financial Education, 30, 9-25.

10. Kolb, D.A. (1985). Experiential Learning: Experience as the Source of Learning and Development. Englewood Cliffs: Prentice Hall.

11. Koppenhaver, G.D. (1993). An evaluation of three bank management simulations: Preliminary results. Financial Practice and Education, 3(2), 89-96.

12. Levkin, B. J. (2005, Summer). Some evidence regarding computer-based financial instrument trading simulations and their use as an assessment tool. Journal of Financial Education, 31, 23-33. 
13. McClatchey, C.A., \& Kuhlemeyer, G.A. (2000). Incorporating stock market games into the classroom: A survey of faculty teaching investments. Financial Practice and Education, 10(2), 201-221.

14. Mukherji, S. (2003, Summer). A spreadsheet project for an analyst's report on a common stock. Journal of Financial Education, 29, 80-97.

15. Nunnally, B. H., Jr., \& Evans, M.D. (2003, Spring). Case teaching and the integrative process. Journal of Financial Education, 29, 75-86.

16. Pozo, S., \& Stull, C. A. (2006, May). Requiring a math skills unit: Results of a randomized experiment. American Economics Review. 


\section{NOTES}

